\title{
RETRATOS EM CANTONEIRAS: IMAGENS DO RIO DE JANEIRO BELLE ÉPOQUE EM JOÃO DO RIO E LIMA BARRETO
}

\author{
Rosa GENS \\ Universidade Federal do Rio de Janeiro \\ rosagens@uol.com.br
}

Resumo: O artigo trabalha com a noção de Belle Époque no panorama da cidade do Rio de Janeiro, intencionando a leitura do processo de dimensionamento do espaço e sua figuração na literatura. Nessa trajetória do pensar, elege dois escritores do início do século XX - João do Rio e Lima Barreto - com posturas diferenciadas, procurando atravessar a Belle Époque e o Rio de Janeiro com mobilidade de reflexão.

Palavras-chave: Belle Époque. Rio de Janeiro. João do Rio. Lima Barreto. Ficção brasileira.

Abstract: The article works with the concept of Belle Époque in the city of Rio de Janeiro, aiming at the reading of the process of change of space and its presentation in literature. On that path the article elects two writers from the beginning of the twentieth century - João do Rio e Lima Barreto - occupying different positions, and tries to go through the Belle Époque and Rio de Janeiro with mobility of reflection.

Keywords: Belle Époque. Rio de Janeiro. João do Rio. Lima Barreto. Brazilian fiction.

Quando se procurava, nas últimas décadas do século passado, obter um panorama da literatura brasileira nos primeiros anos do século, muito pouco poderia ser encontrado. Entre os limites do realismo/naturalismo, parnasianismo e simbolismo e o aparecimento de um novo estilo ficava um hiato que, por convenção, denominou-se prémodernismo. A imagem que era passada pela crítica fixava anos sem rosto, sem um perfil identificável, apontando ora para o passado ora para o novo, que se intitulava moderno. $\mathrm{O}$ que não seria a rigor um período tornou-se, alicerçado em uma visão deslumbrada pelo vigor modernista.

O modernismo, no seu âmbito de valoração, desqualificou narrativas que não exibissem visíveis cortes formais e temáticos com a tradição. Na sua ânsia de negar o passado, encobriu manifestações de diversas esferas. A verdade moderna foi alçada à categoria de bem supremo e os anos 20 assistiram à consagração de uma crítica que não tolerou, muitas vezes, desvios do universo que se denominava moderno.

\begin{tabular}{|l|l|l|l|l|}
\hline Pensares em Revista & São Gonçalo, RJ & n. 1 & 66-75 & jul.-dez. 2012 \\
\hline
\end{tabular}


Nesta segunda década do século XXI, a rota de esclarecimento foi deslocada, e entende-se que o moderno só pode ser compreendido se estudarmos, igualmente, sua origem e preparação. Não estaria, assim, na especificidade do moderno sua real dimensão, e sim nos antecedentes e prelúdios. Pode acontecer, também, de a rota desviar-se para esquecer um pouco o moderno, ou, então, extraviar-se para manifestações artísticas situadas fora de um contexto moderno por excelência. Ou que a reflexão sobre a linearidade da evolução não mais se coloque como preponderante nas linhas de pensamento, e passemos a buscar o individual.

É inegável que os primeiros anos do século XX aparecem aos nossos olhos envoltos em uma aura de mudança e transformação. Em outras palavras, surgem como uma época movimentada culturalmente, em que salões, cabarés, confeitarias, conferências cruzam-se como espaços possibilitadores de encontro e divulgação da arte. Ganharam, por um fenômeno de distanciamento, lugar de destaque, desenhando o perfil de um tempo de ouro, imagem passada por uma parte dos críticos que vêm se debruçando sobre ele.

As ideias sobre o período sofreram, portanto, revisões. Lúcia Miguel Pereira escreve sobre a ficção brasileira de 1870 a 1920 nos anos 20 do século XX; Alfredo Bosi apresenta o volume Pré-modernismo, datado de 1970; a Fundação Casa de Rui Barbosa patrocina um ciclo de estudos sobre o tema em 1986, que depois se torna uma publicação de referência. Os artigos de José Paulo Paes, abordando o art-nouveau, na literatura brasileira, nascem nos anos 80, embora anteriormente o crítico já houvesse indicado o "vazio" da crítica no que tange às primeiras décadas do século. Surge, também, o estudo de Jeffrey D. Needel, Belle époque tropical, e o ensaio de Flora Süssekind, Cinematógrafo das letras. Paralelamente a essas tentativas de interpretação do período, globalizantes, nascem estudos que centralizam suas preocupações em determinado autor, obra, ou tema, e que se adensam, demonstrando o vigor que o período incita.

João do Rio, em 1904, prenunciava, em sua enquete com os escritores da época, $O$ momento literário, mudanças no circuito da obra artística. Aproveitava-se de transformações ocorridas na paisagem literária fim/início do século e soube ler o espírito de mudança existente no ar. Referenciava que

\begin{tabular}{|l|l|l|l|l|}
\hline Pensares em Revista & São Gonçalo, RJ & n. 1 & 66-75 & jul.-dez. 2012 \\
\hline
\end{tabular}


Hoje o escritor trabalha para o editor e não manda vender como José de Alencar e Joaquim Manuel de Macedo por um preto de balaio no braço, as suas obras de porta em porta, como melancias e tangerinas. Uma nova necessidade infiltrou-se nos nossos hábitos: a necessidade de higiene e do confortável. O escritor precisa de higiene, de cuidados, de luxo (RIO, 1994, p. 294).

As relações de produção capitalista alcançam o país, movimentam as artes e remodelam cidades. A Belle Époque, à brasileira, compreende as duas primeiras décadas do século XX, num prisma de vertigem, boêmia, desencanto, tradição e lances do moderno. A cidade do Rio de Janeiro, no período, sofre um processo de remodelação e seu grande símbolo, a Avenida Central (atual Rio Branco), é aberta a golpes de marreta no espírito do "bota-abaixo", impulsionado pelo prefeito Pereira Passos. A Avenida estende-se como a grande vitrine de uma cidade-capital que precisa vender sua imagem de moderna, civilizada. E, entre os cronistas que por ela passam, encontra-se João do Rio.

Este foi o pseudônimo mais célebre de João Paulo Alberto Coelho Barreto, carioca nascido em 1881, em um sobrado da Rua do Hospício (hoje Buenos Aires). Escritor que começa cedo, aos dezoito anos, e logo após torna-se famoso, ao lançar uma série de reportagens devassando os cultos africanos, os rituais satânicos e as vertentes religiosas da época. O tom era sensacionalista e agradou os leitores, que o tornam um sucesso no jornal. As crônicas foram reunidas em volume intitulado As religiões do Rio (1905). Na esteira do sucesso alcançado, abre-se uma nova sequência de artigos, tendo como assunto a cidade, a rua, seus habitantes. O volume $A$ alma encantadora das ruas foi publicado em 1908, reunindo textos que vieram à luz na Gazeta de notícias e na revista Kosmos. A João do Rio deve-se o mérito de mesclar reportagem e crônica, fazendo da cidade sua grande personagem, desdobrada em facetas que permitem a sua compreensão.

A obra se inicia pela crônica que tem por título "A Rua". Nela, o narrador-repórter privilegia a rua como imagem, toma-a como espaço possível de dimensionamento do mundo. Dessa forma, fornece ao leitor, que já não é o mesmo do jornal, a chave de leitura para os textos: é preciso percorrer as páginas (e a cidade) sentimentalmente. Sucedem-se metáforas nessa configuração - a rua é mulher, sulco, o aplauso dos medíocres, dos infelizes, dos miseráveis da arte, é a transformadora das línguas, um ser

\begin{tabular}{|l|l|l|l|l|}
\hline Pensares em Revista & São Gonçalo, RJ & n. 1 & 66-75 & jul.-dez. 2012 \\
\hline
\end{tabular}


vivo e imóvel. A voz narrativa, desdobrada entre flâneur e cronista, dá-lhe alma, incorpora-a subjetivamente. Aliás, a própria atitude de flanar é estimulada pelo autor, merecendo longas considerações:

Flanar! Aí está um verbo universal sem entrada nos dicionários, que não pertence a nenhuma língua! Que significa flanar? Flanar é ser vagabundo e refletir, é ser basbaque e comentar, ter o vírus da observação ligado ao da vadiagem. Flana é ir por aí, de manhã, de dia, à noite, meter-se nas rodas da populaça, admirar o menino de gaitinha ali à esquina, seguir com os garotos e o lutador de Cassino vestido de turco, gozar nas praças os ajuntamentos defronte das lanternas mágicas. [...]

É vagabundagem? Talvez. Flanar é a distinção de perambular com inteligência! Nada como o inútil para ser artístico (RIO, 1987, p. 5).

O cronista afirma: "Eu fui um pouco esse tipo complexo, e, talvez por isso, cada rua é para mim um ser vivo e imóvel". Nessa personificação, tudo se dinamiza em imagens que, muitas vezes, tendem ao feminino: "Vede a Rua do Ouvidor. É a fanfarronada em pessoal, exagerando, mentindo, tomando parte"; "há ruas que, pouco honestas no passado, acabaram tomando vergonha - a da Quitanda". E a rua termina por se revelar como a "a mais igualitária, a mais socialista, a mais niveladora das obras humanas".

No volume, o autor começa, portanto, situando a rua por um processo imagístico que se embasa na emotividade, o que servirá de ponto de partida para a caracterização do humano. Organiza seus textos - instantâneos da cidade - demarcados por áreas de significação. Após o texto de abertura, encontram-se "O que se vê nas ruas", "Três aspectos da miséria", "Onde às vezes termina a rua" e "A musa das ruas". Arruma, assim, para o leitor, o itinerário de leitura, e, é claro, explora a emoção a cada passo do trajeto.

$\mathrm{Na}$ aventura de conhecer a cidade do Rio de Janeiro, a óptica é a do flâneur - foco móvel, que não se fixa em nenhum espaço, permitindo uma visão de passagem. $O$ flâneur circula por entre ruas e becos, observa e entrevista tipos humanos, todavia não se mistura, permanecendo o comentador distanciado, o intelectual burguês que se compraz ao se disfarçar entre as camadas populares. É um olhar que não tem raízes, perambula, movido pela curiosidade e pelo sensacionalismo. Vai de um ponto a outro da cidade, de figura em figura, como lhe permite o movimento solto e, num tom por

\begin{tabular}{|l|l|l|l|l|}
\hline Pensares em Revista & São Gonçalo, RJ & n. 1 & $66-75$ & jul.-dez. 2012 \\
\hline
\end{tabular}


vezes confidencial e intimista, convida o leitor, que pode sentir o mesmo amor pelas ruas, a flanar pelo Rio de Janeiro.

Mas que cidade é a retratada por João do Rio? Em A alma encantadora das ruas, fundamentalmente a dos espaços preenchidos pelos habitantes que não frequentam Botafogo. O Rio aparece, através de seus relatos, como uma grande cidade e, como tal, apresenta seus espaços hierarquizados. $\mathrm{E}$ as figuras apreendidas pelo cronista por vezes nem mesmo encontram seu lugar, tão baixa a condição social, tão à margem se acham do sistema de produção convencional. Basta conferir: "O Rio tem também as suas pequenas profissões exóticas, produto da miséria ligada às fábricas importantes, aos adelos, ao baixo comércio; o Rio, como todas as grandes cidades, esmiúça no próprio monturo a vida dos desgraçados".

A cidade, que se vendeu como civilizada, mas construiu seu símbolo de evolução, a Avenida Central, às custas dos desalojados (cerca de vinte mil), empurrando-os do meio de seu movimento, banindo-os do centro para a periferia ou motivando a formação da favela, guarda em seu interior as sombras e o crime. A cidade-inferno comparece aos textos relativos à Casa de Detenção e a outros, em que o bas-fond urbano é iluminado. Violências, crimes, cenas nada encantadoras passam aos olhos do leitor, filtradas pela piedade do narrador-repórter. Que não perde ocasião de dar um toque melodramático às situações, como no trecho seguinte:

A essa mulher bastara perder o apoio na sociedade, para acabar no horizonte fechado de correcional todos os sonhos de ambição, todas as ideias felizes que os pais depositaram no seu espírito. Que lhe servia a visão superior do mundo na cloaca do crime da luxúria? (RIO, 1987, p. 169).

No entanto, o autor também acerta na dose, e, com frequência, são nítidos os retratos da cidade que mostra ao leitor. Mais do que tudo, possibilita a visão de espaços ainda desordenados, que a reforma urbana não conseguira lotear com eficácia. Curiosa é, também, no desdobrar do itinerário de leitura, a crônica final, "A musa das ruas", em que a escrita literária se funde ao traçado da cidade e as ruas ganham alma na poesia popular. Ao leitor de João do Rio cabe, portanto, a tarefa de acompanhar o cronista, flanando com ele, para descobrir o encanto e a miséria das ruas. Ou, se preferir conhecer um outro lado da produção da produção de Paulo Barreto, ir a um chá na Pérgula do

\begin{tabular}{|l|l|l|l|l|}
\hline Pensares em Revista & São Gonçalo, RJ & n. 1 & $66-75$ & jul.-dez. 2012 \\
\hline
\end{tabular}


Copacabana Palace, lendo as crônicas mundanas do Pall-Mall Rio. Ou ainda, se quiser a vertigem da cidade moderna, os textos de Cinematógrafo. Faces do disfarce habilmente utilizado pelo autor, as obras de Paulo Barreto arranham o verniz de superfície da cidade e sumariam traços de uma metrópole com fisionomia moderna.

Mas em um ponto se unem a elas as obras de um outro escritor, Lima Barreto que, como João do Rio, pontuou seus escritos com a vivência do Rio de Janeiro. Tratase de outro boêmio a cristalizar imagens urbanas, dessa vez, através da óptica da ironia e da revolta.

Afonso Henriques de Lima Barreto faleceu em $1^{\circ}$ de novembro de 1922 - ano da Semana de Arte Moderna - mas alijado de seu circuito. Alguns meses antes, saiu da "Vila Quilombo" (assim o escritor denominava sua casa em Todos os Santos) para presenciar as festividades do centenário da Independência e em homenagem ao Rio. Seu amor à cidade encontra-se presente nesse gesto, que bem demonstra a sintonia entre o autor e o espaço urbano. Vagava pelas ruas, sempre, andarilho/pensante, observando cenas, falas, prédios e ruas, numa ânsia constante de descobertas. Na poeira dos caminhos, escreve o percurso das vias do subúrbio ao centro; com seu aspecto desleixado, fere a burguesia bem arrumada; com o pensamento independente, mostra o inconformismo que fundamenta a sua obra.

$\mathrm{O}$ autor deixou dezessete volumes que totalizam seus escritos. Ao nos defrontarmos com a crítica a suas obras, a tendência é de hierarquizá-las em boas ou más, como se pudessem medir seus textos por níveis de acabamento. A impressão que nos advém, se embarcarmos na onda dos críticos, é a de um conjunto que peca pelo desnível, exibindo-se de forma heterogênea. Entretanto, o próprio Lima nos dá a chave para entendermos o que é percebido como desnível - nunca desejou a pose da linguagem literária oficial. Nem da linguagem nem a do escritor, bem visto nas rodas intelectuais.

Entre o subúrbio e Botafogo, o escritor transitou sem identificações. Nem lá, nem em qualquer outro lugar se aquietava, sempre em trânsito pelos espaços de um Rio de Janeiro "estrambótico". É evidente que não poderia manter contato com uma literatura que se vendia como "sorriso da sociedade", na expressão de Afrânio Peixoto, nem divisar, à maneira de Paulo Barreto, um Rio de Janeiro metropolizado, internacional, moderno, mas que guarda o arcaico e o primitivo. Em suas páginas, a imagem da cidade 
que salta é multifacetada, destacando a reconstrução das fronteiras entre o público e o privado, as transformações dos bairros, os espaços populares que são arrasados para se transformarem em ricos, redefinindo os lugares de ocupação social.

Para que melhor se alcance o gesto de Lima Barreto em relação ao Rio de Janeiro, cumpre citar um texto ficcional - Vida e morte de M. J. Gonzaga de Sá. Nele, o autor constrói Augusto Machado, biógrafo a quem caberá a tarefa de iluminar a vida do protagonista, sintonizado à cidade, como se pode observador no capítulo "O passeador":

O que me maravilhava em Gonzaga de Sá era o abuso que fazia da faculdade de locomoção. Encontrava-o em toda a parte, e nas horas mais adiantadas. Uma vez, eu ia de trem, vi-o pelas tristes ruas que marginam o início da Central; outra vez, era um domingo, encontrei-o na Praia das Flechas, em Niterói. Nas ruas da cidade, já não me causava surpresa vê-lo. Era em todas, pela manhã e pela tarde. Segui-o uma vez. Gonzaga de Sá andava metros, parava em frente a um sobrado, olhava, olhava e continuava. Subia morros, descia ladeiras, devagar sempre, e fumando voluptuosamente, com as mãos atrás das costas, agarrando a bengala (BARRETO, 1990, p. 40).

Da mesma forma que Gonzaga de Sá abusa da faculdade de locomoção, Lima Barreto propaga, em seus escritos, considerações sobre situações, costumes, tipos e locais do Rio de Janeiro, em uma atitude que denuncia o seu amor pela cidade. Mas voltemos ao capítulo "O passeador", situando agora as palavras da personagem:

- Pense que toda a cidade deve ter sua fisionomia própria. Isso de todas se parecerem é gosto dos Estados Unidos; e Deus me livre que tal peste venha a pegar-nos. (...)

Se considerarmos a topografia do Rio, havemos de ver que as condições do meio físico justificam o que digo. As montanhas e as colinas afastam e separam as partes componentes da cidade. (...)

É que o Rio de Janeiro não foi edificado segundo o estabelecido na teoria das perpendiculares e oblíquas. Ela sofreu, como todas as cidades espontâneas, o influxo do local em que se edificou e das vicissitudes sociais por que passou, como julgo ter dito já (BARRETO, 1990, p. 42).

Não é raro o leitor deparar-se com um comentário sobre o traçado da cidade e sua distribuição. Lima Barreto visualiza o Rio como um todo, estudava sua planta, criticava modificações; em suma, denunciava o perigo existente no projeto de urbanização. A

\begin{tabular}{|l|l|l|l|l|}
\hline Pensares em Revista & São Gonçalo, RJ & n. 1 & 66-75 & jul.-dez. 2012 \\
\hline
\end{tabular}


derrubada do velho significava, para ele, o apagar das marcas da vida da cidade, que sofria de perda de memória e do risco de esfacelamento da identidade.

Por outro lado, recusa a modernidade, pois nela entrevê a falência do projeto nacionalista. A busca de ordenação do espaço urbano, o caminho de um pretenso progresso, fazem parte, em sua opinião, do mesmo movimento de exclusão do popular e ganho de terreno por parte do estrangeiro. Não há nada de nostálgico, no entanto, na visão do escritor. O que se critica é o plano urbanístico, que se fez como se a cidade fosse simples maquete, em que a vida não pulsasse.

Do espetáculo do mar e do céu no terraço do Passeio Público, ao do povo à noite na Avenida, passando pelas prostitutas na Rua do Ouvidor, faz-se o ritmo da cidade. Que, por vezes, também pode ser entrevisto em trens e bondes. É notável a constância de imagens urbanas deflagradas pelo autor, principalmente em suas crônicas, por intermédio de meios de locomoção. Figuras e espaços são dimensionados pela visão propiciada em movimento, ou mesmo pela parada na estação, eixo da vida dos subúrbios.

A cidade de Lima Barreto é, portanto, hierarquizada, em que se tornam visíveis redes de controle do espaço urbano. O histórico dos bairros, dados relativos a prédios, observações referentes à arquitetura, passam por seus textos e revelam um escritor preocupado com os nexos internos que constroem a vida urbana. O espaço periférico da cidade, em comparação a Botafogo e Laranjeiras, revela o estabelecimento de uma geografia social do espaço urbano, em episódios caros ao autor. A especificidade do traçado da cidade, em consonância com os objetivos socioeconômicos, sua expansão para a zona sul, a desordem obtida na busca da organização utilitária do espaço cotidiano aparecem em sua obra sob o crivo da denúncia e da revolta.

O que não impede o lirismo e a emoção de marcarem algumas passagens, como do Diário do hospício, em que o autor/narrador, do Hospital dos Alienados, espia a Baía de Guanabara:

Dia de São Sebastião. Um dia feio, nevoento. Olho a baía de Botafogo, cheio de tristeza. Não acho tão bela como sempre achei. Os longes dos Órgãos não se veem; estão mergulhados em névoas. As montanhas de Niterói estão sem o cobalto de sempre; e as manchas dos cortes e chanfraduras nelas aparecem como chagas. O casario está mergulhado, confuso, não se desenha bem no horizonte. Tudo é triste (BARRETO, 1993, p. 59).

\begin{tabular}{|l|l|l|l|l|}
\hline Pensares em Revista & São Gonçalo, RJ & n. 1 & 66-75 & jul.-dez. 2012 \\
\hline
\end{tabular}


Existem escritores que tratam as cidades como mero pano de fundo em seus textos; outros, convertem-nas no próprio tema de suas produções. João do Rio e Lima Barreto, por diferentes caminhos, quer pela senda do melodrama, quer da indignação, ou do lirismo essencial, capturaram, em palavras, as transformações ocorridas no Rio de Janeiro, nas décadas de abertura do século. Outras produções cortejaram também a cidade, como as de Carmen Dolores (1852-1910), Benjamin Costallat (1897-1961), Chrysanthème, entre outras. Esses retratos ficaram, e nem mesmo importa se o foco não for nítido, em momentos, já que subsistem como tentativas de interpretação do significado das mudanças dos contornos da cidade. E a nós, leitores do século XXI, permitem o exercício de comparação frente à cidade que vemos hoje, em que novas reformas ocupam a cena, em época de eventos e transformações.

Interessante é notar, também, que tanto João do Rio quanto Lima Barreto permaneceram à margem das histórias da literatura canônicas por longo tempo, sepultados, no mais das vezes, pelo tom de ruptura que empolgou os debates modernistas. $\mathrm{O}$ primeiro voltou à cena por volta dos anos 80 do século $\mathrm{XX}$, cortejado inicialmente pelos estudos culturais, enquanto o segundo teve sua obra republicada nos anos 50, mas só mereceu um olhar mais atento da crítica nos anos 70, sob a virada do marxismo, capaz de encontrar na produção do autor componentes gratos ao seu circuito de abordagem. Hoje as edições se sucedem, assim como os estudos acadêmicos, demonstrando o vigor da produção literária de ambos e o interesse vivificado.

\section{Referências bibliográficas:}

BARRETO, Afonso Henriques de Lima. Diário do hospício; O cemitério dos vivos. Rio de Janeiro: Secretaria Municipal de Cultural, 1994.

Vida e morte de M. J. Gonzaga de Sá. Rio de Janeiro: Garnier, 1990.

NEEDEL, Jeffrey. Belle époque tropical. São Paulo: Companhia das Letras, 1993.

RIO, João do. A alma encantadora das ruas. Rio de Janeiro: Secretaria Municipal de Cultura, 1987.

O momento literário. Rio de Janeiro: Fundação Biblioteca Nacional, 1994.

\begin{tabular}{|l|l|l|l|l|}
\hline Pensares em Revista & São Gonçalo, RJ & n. 1 & 66-75 & jul.-dez. 2012 \\
\hline
\end{tabular}


Recebido em: 21 de junho de 2012.

Aprovado em: 08 de setembro de 2012.

\section{Sobre a autora:}

Doutora em Letras (Letras Vernáculas) pela Universidade Federal do Rio de Janeiro (1997). Mestra em Letras (Letras Vernáculas) pela Universidade Federal do Rio de Janeiro (1981). Atualmente é professora associada da Universidade Federal do Rio de Janeiro. Tem experiência na área de Letras, com ênfase em Literatura Brasileira, atuando nos Programas de Pós-Graduação em Letras Vernáculas da Faculdade de Letras da UFRJ. 